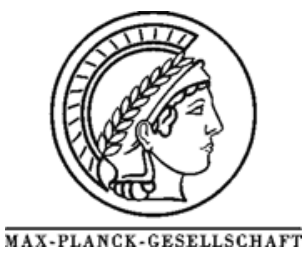

\title{
Synthesis of new $\mathrm{RuO}_{2} @ \mathrm{SiO}_{2}$ composite nanomaterials and their application as catalytic filters for selective gas detection
}

\author{
S. Jansat ${ }^{\dagger}$ K. Pelzer, ${ }^{\dagger}$ J. García-Antón, ${ }^{\dagger}$ R. Raucoules,${ }^{\dagger}$ K. Philippot,${ }^{\dagger}$ A. Maisonnat, ${ }^{\dagger}$ B. Chaudret,${ }^{\dagger}$ \\ Y. Guari, ${ }^{\star}$ A. Mehdi, ${ }^{\star}$ C. Reyé, ${ }^{\ddagger}$ R.J.P. Corriu. ${ }^{*}$ \\ 'Laboratoire de Chimie de Coordination du CNRS (LCC-CNRS), 31077 Toulouse Cedex 04, France \\ Fax: (+33)561333100, e-mail karine philippot@lcc-toulouse.fr, \\ Institut Charles Gerhardht, UMR 5253, Chimie Moléculaire et Organisation du Solide, 34095 Montpellier cedex 5, \\ France, Fax : (+33)467143852, e-mail: yannick.guari@univ-montp2.fr
}

Published Online: 4 Oct 2007

\begin{abstract}
$\mathrm{RuO}_{2} @ \mathrm{SiO}_{2}$ nanomaterials have been prepared using hybrid mesostructured silica $(\mathrm{EtO})_{2} \mathrm{P}(\mathrm{O})\left(\mathrm{CH}_{2}\right)_{3} \mathrm{SiO}_{1.5} / \mathrm{xSiO}_{2}(\mathrm{x}=9,16)$ by anchoring the metal precursor $[\mathrm{Ru}(\mathrm{COD})(\mathrm{COT})](\mathrm{COD}=1,3$-cyclooctadiene, $\mathrm{COT}=1,3,5$-cyclooctatriene) within the pores of the organized silica matrix taking profit of the phosphonate moieties followed by i) decomposition under dihydrogen atmosphere at room temperature in THF to achieve ruthenium nanoparticles containing materials and ii) a solid state thermal treatment at $450^{\circ} \mathrm{C}$ under air. The $\mathrm{Ru}$ and $\mathrm{RuO}_{2}$ nanoparticles containing materials have been characterised by elemental analysis, Transmission Electron Microscopy (TEM), X-Ray Diffraction (XRD), nitrogen sorption measurements and ${ }^{31} \mathrm{P}$ and ${ }^{13} \mathrm{C}$ Nuclear Magnetic Resonance (NMR). The so-obtained $\mathrm{RuO}_{2} @ \mathrm{SiO}_{2}$ nanomaterials were evaluated as catalytic filters when deposited onto gas sensors for the preferential detection of propane in a multicomponent gas mixture propane/carbon monoxide/nitrogen dioxide.
\end{abstract}

Keywords: ruthenium, ruthenium oxide, nanoparticle, ordered silica, hybrid nanomaterial, catalytic filter, gas sensor, CO oxidation, selectivity

\section{Introduction}

Metallic or semiconducting nanoparticles are the subject of intense research owing to their unique physical properties arising from factors like large surface to volume ratio and quantum effects on charge carrier confinement. ${ }^{1}$ This research is driven by potential applications in electronics, optics, catalysis, ceramics and magnetic data storage. In this respect, nanomaterials attract more and more attention for the development of new gas sensing systems able to respond to growing industrial and societal demands.

Metal oxides are widely employed as sensitive elements in gas sensors ${ }^{2}$ and commercial devices produced by classical ceramic process have been available for a long time. ${ }^{3}$ If such devices are able to detect low concentration of flammable or toxic gases at a ppm level, their lack of selectivity and long term stability remains their major drawback and improving the cross sensitivities between gases such as $\mathrm{CO}$, hydrocarbons and $\mathrm{NO}_{2}$ is still a major problem. Enhancement of the sensor performances can be achieved through $i$ ) an accurate control of the morphology in the nanometer range, of the composition and of the surface state of the sensing materials ${ }^{4,5}$ ii) the integration of the sensor components on micro machined silicon platforms ${ }^{6}$ iii) the optimization of the working temperature of the sensitive layer, ${ }^{7}$ of the operating mode and the signal processing, ${ }^{8}$ and iv) by the use of filters exhibiting selective gas retention or conversion properties. ${ }^{9}$

The use of filters combining catalyst-loaded mesoporous materials represents a very attractive way to improve the selectivity of the sensor toward a target gas and to overcome the classical problem of saturation exhibited by passive filtering membranes.. ${ }^{9 \mathrm{e}}$ The filtering efficiency of such a material, in term of selectivity, reproducibility and long term stability, nevertheless asks for requirements of crucial importance regarding its composition and its morphology ${ }^{10}$ i.e. homogeneous dispersion and high surface area of the active sites in the mesoporous support; homogeneous distribution of size-controllable pore channels of the support; immobilization of the active sites 


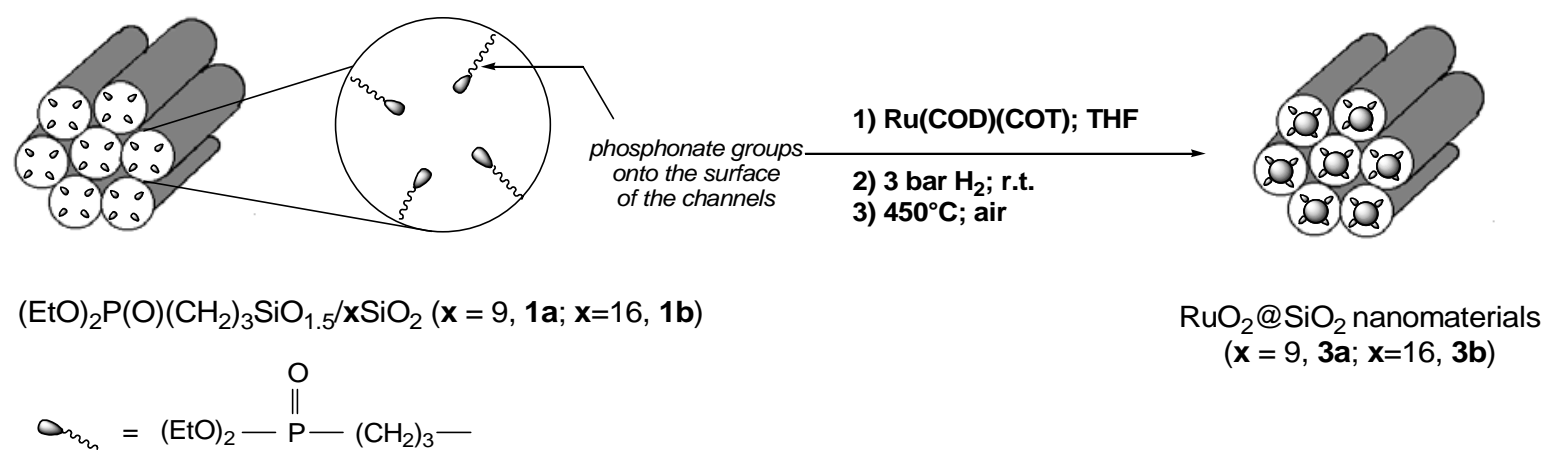

$$
(\mathrm{EtO})_{2} \mathrm{P}(\mathrm{O})\left(\mathrm{CH}_{2}\right)_{3} \mathrm{SiO}_{1.5} / \mathbf{x} \mathrm{SiO}_{2}\left\{\begin{array}{l}
\mathbf{x}=9, \mathrm{SiO}_{2}=\mathbf{1 a}, \mathrm{Ru} @ \mathrm{SiO}_{2}=\mathbf{2 a}, \mathrm{RuO}_{2} @ \mathrm{SiO}_{2}=\mathbf{3 a} \\
\mathbf{x}=16, \mathrm{SiO}_{2}=\mathbf{1 b}, \mathrm{Ru} @ \mathrm{SiO}_{2}=\mathbf{2} \mathbf{b}, \mathrm{RuO}_{2} @ \mathrm{SiO}_{2}=\mathbf{3 b}
\end{array}\right.
$$

Scheme: Schematic representation for the synthesis of $\mathrm{Ru}$ and $\mathrm{RuO}_{2}$ nanoparticles in the mesostructured silica.

Templated mesostructured silica materials exhibit periodic and size-controllable pore channels $(2-10 \mathrm{~nm})$ and high specific surface area. Since their initial discovery, ${ }^{11}$ such materials have been considered as ideal nanoreactors for the deposition or the growth of various guest molecules. Among them, the introduction of metallic nanoparticles constitutes a judicious choice to prepare nanocomposite materials able to display catalytic properties ${ }^{12}$ and to find application as catalytic filters. ${ }^{9 e, f}$

We and others have already explored a method for the introduction of metallic nanoparticles within functionalized hybrid mesostructured silica. ${ }^{13-17}$ This method allows in one-step i) the selective anchorage of the metal precursor on the organic functions specially introduced within the pores of the mesostructured material, ii) a high metal loading and iii) a homogeneous dispersion of the metal throughout the host structure. The second step consists in the chemical reduction/decomposition of the metal precursor incorporated into the pores of the material. Some of us have developed a method for the controlled growth of nanoparticles based on the decomposition of organometallic compounds in mild conditions. ${ }^{18}$ Since this organometallic approach was successfully applied for the synthesis of ruthenium nanoparticles in solution ${ }^{19}$ or onto various supports, ${ }^{20}$ its combination with the use of functionalized mesostructured silica appeared as a favourable and simple way to access to well-controlled and welldispersed ruthenium nanoparticles exclusively within the pores of the host matrix. A subsequent thermal treatment under air allowed the transformation of the ruthenium nanoparticles into ruthenium oxide ones within the silica host.

In this paper, we report a simple and reproducible preparation of composite nanomaterials made of ruthenium or ruthenium oxide nanoparticles embedded in a mesostructured silica matrix. The ruthenium oxide containing composite materials were evaluated as catalytic filters for gas sensors for the preferential detection of propane in a multicomponent gas mixture.

\section{Results and Discussion}

The growth of $\mathrm{Ru}$ and $\mathrm{RuO}_{2}$ nanoparticles within the pores of ordered mesoporous silica, has been achieved through impregnation of hybrid mesostructured silica $(\mathrm{EtO})_{2} \mathrm{P}(\mathrm{O})\left(\mathrm{CH}_{2}\right)_{3} \mathrm{SiO}_{1.5} / \mathrm{xSiO}_{2}(\mathrm{x}=9: \mathbf{1 a}, \mathrm{x}=16: \mathbf{1 b})$ with the organometallic precursor $[\mathrm{Ru}(\mathrm{COD})(\mathrm{COT})]$ taking profit of the phosphonate groups present within the pores of the silica matrices to favour the anchorage of the metal precursor. The organometallic precursor has been further decomposed at room temperature under dihydrogen pressure to afford the metallic ruthenium nanoparticles. A subsequent thermal treatment of the as-obtained nanocomposites under air led to $\mathrm{RuO}_{2} @ \mathrm{SiO}_{2}$ nanomaterials with different amounts of $\mathrm{RuO}_{2}$ nanoparticles (Scheme).

\subsection{Ruthenium nanoparticles growth within hy- brid mesostructured silicas}

An impregnation/hydrogenation (I/H) two-step cycle was performed to prepare the ruthenium nanoparticles containing nanocomposites. One, two or three $\mathrm{I} / \mathrm{H}$ cycles were applied to the mesostructured materials $(\mathrm{EtO})_{2} \mathrm{P}(\mathrm{O})\left(\mathrm{CH}_{2}\right)_{3} \mathrm{SiO}_{1.5} / \mathrm{xSiO}_{2}(\mathrm{x}=9: \mathbf{1 a}, \mathrm{x}=16: \mathbf{1 b})$. The ruthenium loading for the resulting nanocomposite materials $[\mathrm{Ru}]_{\mathrm{y}}(\mathrm{EtO})_{2} \mathrm{P}(\mathrm{O})\left(\mathrm{CH}_{2}\right)_{3} \mathrm{SiO}_{1.5} / \mathrm{xSiO}_{2}\left(\mathrm{Ru} @ \mathrm{SiO}_{2} ; \mathrm{x}=9\right.$, 2a; $\mathbf{x}=16,2 \mathbf{b})$ was inferred from elemental analyses (Table 1). From these results, it can be seen that the maximum of ruthenium content is obtained after two $\mathrm{I} / \mathrm{H}$ cycles. For this reason and in order to avoid uncontrolled growth of ruthenium nanoparticles out of the pores of the silica grains, all subsequent experiments and analyses were performed with nanocomposite materials resulting from only one or two I/H cycles. The comparison between nanocomposite materials 2a and $\mathbf{2 b}$ (7.91 and 10.09 wt\% respectively for two $\mathrm{I} / \mathrm{H}$ cycles) shows that the amount of incorporated ruthenium nanoparticles is not directly linked 
to the amount of organic groups available in the hybrid

organic-inorganic mesostructured silicas 1a, 1b. $\mathrm{x}$ and $\mathrm{y}$

Table 1: Elemental analysis obtained for materials 1-3

\begin{tabular}{|c|c|c|c|c|c|c|c|c|c|}
\hline $\begin{array}{c}\mathrm{Ru} / \mathrm{SiO}_{2}(\text { wt. } \%) \text { used } \\
\text { for each impregna- } \\
\text { tion step }\end{array}$ & $\begin{array}{c}\text { Type of Nanoma- } \\
\text { terial }\end{array}$ & NanoMaterial & $\begin{array}{c}\text { Number } \\
\text { of } \mathbf{I} / \mathbf{H} \\
\text { cycle } \\
\end{array}$ & $\mathbf{P}[\%]$ & Si [\%] & $\begin{array}{c}\text { Ru } \\
{[\%]}\end{array}$ & $\mathbf{x}^{\mathbf{a}}$ & $\mathbf{y}^{\mathbf{a}}$ & $y / x^{a}$ \\
\hline & $\mathrm{SiO}_{2}$ & 1a $(x=9)$ & 0 & 3.90 & 33.90 & 0 & 8.6 & 0 & 0 \\
\hline \multirow{4}{*}{$7 \%$} & \multirow{2}{*}{$\mathrm{Ru} @ \mathrm{SiO}_{2}$} & \multirow{2}{*}{$2 a$} & 1 & 3.04 & 28.43 & 3.94 & 10.3 & 0.40 & 0.04 \\
\hline & & & 2 & 2.59 & 26.89 & 7.91 & 10.4 & 0.97 & 0.09 \\
\hline & \multirow{2}{*}{$\mathrm{RuO}_{2} @ \mathrm{SiO}_{2}$} & \multirow{2}{*}{ 3a } & 1 & 3.25 & 31.06 & 3.34 & 10.5 & 0.31 & 0.03 \\
\hline & & & 2 & 3.19 & 32.64 & 8.37 & 11.3 & 0.80 & 0.07 \\
\hline \multirow{4}{*}{$1 \%$} & ${\mathrm{Ru} @ \mathrm{SiO}_{2}}$ & $2 a^{\prime}$ & 1 & 3.24 & 30.06 & 0.71 & 10.2 & 0.07 & 0.007 \\
\hline & $\mathrm{RuO}_{2} @ \mathrm{SiO}_{2}$ & $3 a^{\prime}$ & 1 & 3.74 & 36.00 & 0.82 & 10.6 & 0.07 & 0.007 \\
\hline & $\mathrm{SiO}_{2}$ & $1 b(x=16)$ & 0 & 1.90 & 28.43 & 0 & 15.5 & 0 & 0 \\
\hline & & & 1 & 1.93 & 29.31 & 4.90 & 15.7 & 0.78 & 0.05 \\
\hline \multirow[t]{3}{*}{$7 \%$} & ${\mathbf{R u} @ \mathrm{SiO}_{2}}$ & $2 \mathbf{b}$ & 2 & 1.93 & 27.45 & 10.09 & 14.7 & 1.60 & 0.11 \\
\hline & & & 3 & 1.95 & 27.28 & 9.96 & 14.4 & 1.56 & 0.11 \\
\hline & $\mathrm{RuO}_{2} @ \mathrm{SiO}_{2}$ & $3 \mathbf{b}$ & 1 & 1.91 & 27.98 & 5.64 & 15.2 & 0.91 & 0.06 \\
\hline
\end{tabular}
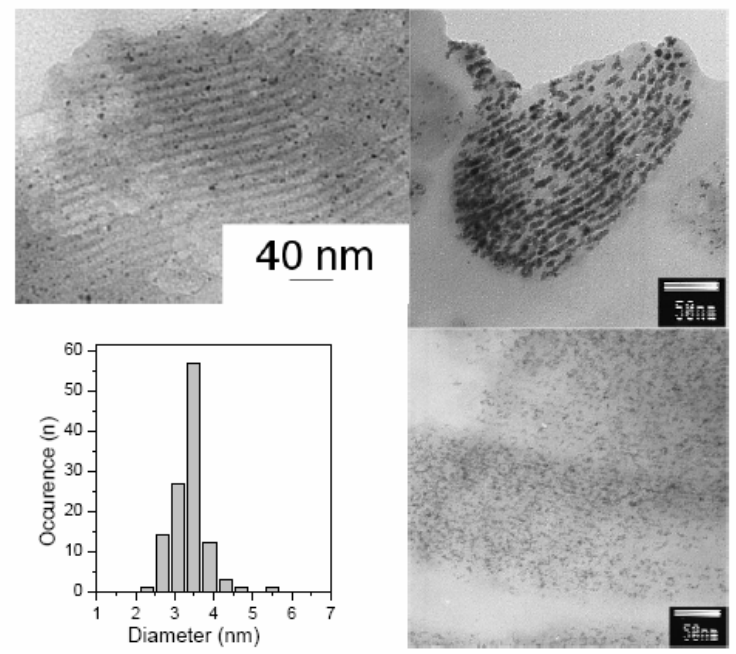

Figure 1: TEM images of nanomaterial 2a obtained after one $\mathrm{I} / \mathrm{H}$, a) with the corresponding $\mathrm{Ru}$ nanoparticles size distribution, b) after two $\mathrm{I} / \mathrm{H}$ cycles, c) and of nanomaterial $\mathbf{2 b}$ obtained after two $\mathrm{I} / \mathrm{H}$ cycles, d).

values and $\mathrm{y} / \mathrm{x}$ ratio reported in table 1 correspond respectively to $\mathrm{SiO}_{2} /(\mathrm{EtO})_{2} \mathrm{P}(\mathrm{O})\left(\mathrm{CH}_{2}\right)_{3} \mathrm{SiO}_{1.5}$, $\mathrm{Ru} /(\mathrm{EtO})_{2} \mathrm{P}(\mathrm{O})\left(\mathrm{CH}_{2}\right)_{3} \mathrm{SiO}_{1.5}$ and $\mathrm{Ru} / \mathrm{SiO}_{2}$ ratios. The presence of $\mathrm{Ru}$ nanoparticles in the mesoporous silica matrix could be attested performing Transmission Electron Microscopy (TEM) analyses on $\mathbf{2 a}$ and $\mathbf{2 b}$ nanomaterials (Figure 1). The TEM images clearly show that the mesostructure of the parent hosts $\mathbf{1 a}, \mathbf{1 b}$ is not damaged after the $\mathrm{I} / \mathrm{H}$ cycles and that ruthenium nanoparticles are present inside the channels. In addition, no external ruthenium nanoparticles were observed outside the channels. Narrow size distributions centred on $3.4 \mathrm{~nm}$ are obtained for the ruthenium nanoparticles in all cases, whatever the starting hybrid silica or the number of $\mathrm{I} / \mathrm{H}$ cycles per

Table 2: BET and XRD data for materials 1-3.

\begin{tabular}{cccccccc}
\hline Material & $\mathrm{I} / \mathrm{H}$ & $\mathrm{S}_{\text {Spec. }}\left[\mathrm{m}^{2} \cdot \mathrm{g}^{-1}\right]$ & $\mathrm{V}_{\mathrm{p}}\left[\mathrm{cm}^{3} \cdot \mathrm{g}^{-1}\right]^{\mathrm{a}}$ & $\mathrm{D}_{\mathrm{p}}[\mathrm{nm}]$ & $\mathrm{d}_{100}$ & $\mathrm{~d}_{110}$ & $\mathrm{~d}_{200}$ \\
\hline la & 0 & 722 & 1.21 & 6.0 & 9.2 & 5.3 & 4.6 \\
\hline 2a & 1 & 465 & 0.46 & 6.0 & 9.4 & 5.5 & 4.7 \\
& 2 & 253 & 0.40 & 6.2 & 9.4 & 5.2 & 4.4 \\
\hline 3a & 2 & 259 & 0.35 & 4.5 & 9.2 & 5.0 & 4.5 \\
\hline lb & 0 & 646 & 1.14 & 7.5 & 10.7 & 6.4 & 5.5 \\
\hline 2b & 1 & 289 & 0.55 & 7.3 & 10.7 & 6.5 & 5.6 \\
& 2 & 198 & 0.37 & 7.3 & 10.8 & 6.9 & 5.8 \\
\hline 3b & 1 & 205 & 0.39 & 6.0 & 10.6 & 6.6 & 5.7 \\
\hline
\end{tabular}

"The total pore volumes were calculated at $\mathrm{p} / \mathrm{p}_{0}=0.9$.

$\mathrm{S}_{\text {Spec. }}=$ Specific surface area, $\mathrm{V}_{\mathrm{p}}=$ Pore volume, $\mathrm{D}_{\mathrm{p}}=$ Pore diameter.

formed. The size of the obtained nanoparticles is similar to the one observed in previous works, in solution ${ }^{19}$ or onto various supports. ${ }^{20}$ The size of the resulting nanoparticles is not governed by the diameter of the pore channels of the mesostructured matrix used. However, the density of nanoparticles increases significantly, when the amount of incorporated ruthenium increases (Table 1), from materials 2a to materials $\mathbf{2 b}$ and from one to two I/H cycles.

The effect of the nanoparticle formation on the structure and the porosity of the host matrix was studied by nitrogen physisorption and X-ray diffraction (XRD) analysis. The structures 1a, 1b show a typical adsorption/desorption isotherm of type IV with an H1 hysteresis loop, as shown on figure $2 \mathrm{a}$ for $\mathbf{1 b}$. The pore sizes were calculated from the desorption branches of the isotherms using the BarretJoyner-Hellenda (BJH) formula (Table 2, Figure 2b). Similar isotherms type and mesoporosity are obtained for the composite nanomaterial $\mathbf{2 b}$ after intrapore growth of the ruthenium nanoparticles proving the preservation of the 
cylindrical pore system. The amount of adsorbed nitrogen, as well as the specific surface determined using the Brun
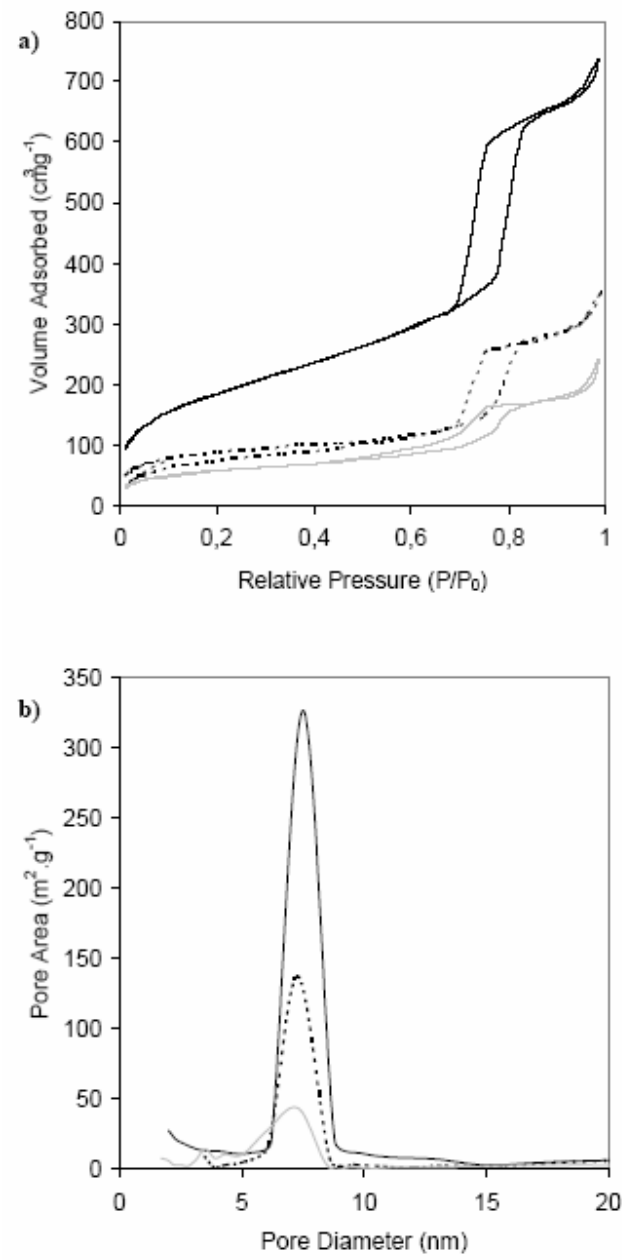

Figure 2: a) Nitrogen adsorption-desorption isotherms and b) BJH pore size distribution calculated from the desorption branch for the hybrid silica $\mathbf{1 b}$ (black, solid line) and the nanocomposites $\mathbf{2 b}$ after one (black, dotted line) and two (grey, solid line) $\mathrm{I} / \mathrm{H}$ cycles.

auer-Emmett-Teller (BET) formula, decreased after formation of the ruthenium nanoparticles for each $\mathrm{I} / \mathrm{H}$ cycle. For the use of the host material 1a, similar behaviours were observed. The decrease of the pore volume and specific surface can not be ascribed only to the additional weight brought by the ruthenium nanoparticles without any other meanings concerning their location within the nanomaterials obtained. To take into account this weight modification due to ruthenium nanoparticles formation, specific surface and pore volume were standardized against the hybrid mesoporous silica (Table 2). Indeed, we still observe a significant decrease of the mesoporous volume and of the pore volume which clearly demonstrates a filling of the pores with the guest species, leading to the conclusion that the nanoparticles are formed inside the pores. The obtained results indicate a degree of filling of the pores for materials 2a, 2b after two I/H cycles of $67 \%$. Such a high degree of filling is not compatible with the amount of ruthenium nanoparticles inserted and is more indicative of a partial blocking of the pores of the mesostructured silica by ruthenium nanoparticles. The powder X-ray diffraction (XRD)

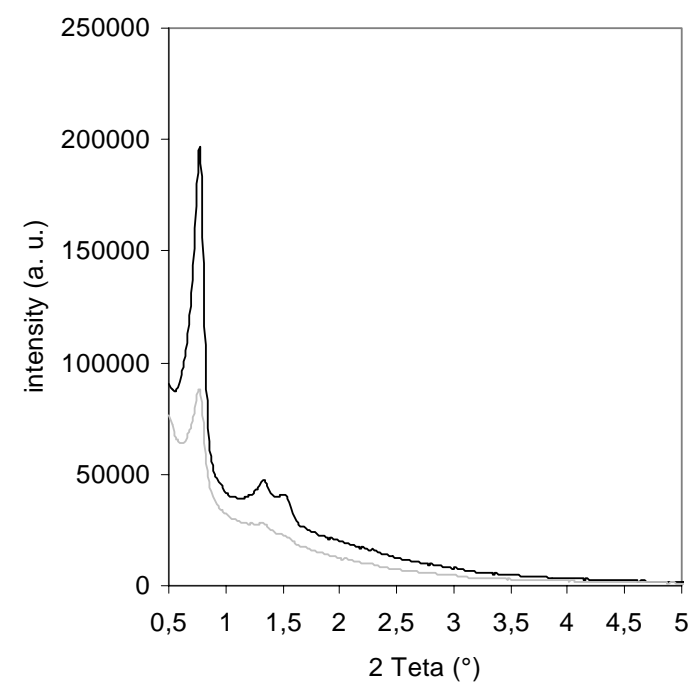

Figure 3: Powder X-ray diffraction patterns within the $2 \theta$ range $\left(0.5-5^{\circ}\right)$ for the hybrid silica $\mathbf{1 b}$ (black, solid line) and the nanomaterial $\mathbf{2 b}$ (grey, solid line) after two I/H cycles.

patterns at $2 \theta\left(0.5-5^{\circ}\right)$ of the hybrid silica phases 1a, $\mathbf{1 b}$ clearly correspond to the space group $P 6 m$ with a sharp peak due to the (100) reflection along with the (110) and (200) reflections. A high degree of long-range order can be assumed according to the reflections at higher diffraction angles $2 \theta$ for both mesoporous host structures. The low angle X-ray diagram of the mesostructured hybrid silica $\mathbf{1 b}$ is given Figure 3 with the one obtained for nanomaterial 2b. After one and two I/H cycles, the XRD peaks of the nanomaterials 2a, 2b were reduced in intensity but did not change their positions proving the conservation of the mesoporous hosts. The intensity of the Bragg reflections originates from the difference in the scattering power between the silica walls and the empty pores. Due to the filling of the pores with ruthenium nanoparticles, the amount of scattering power within the pores is increased, resulting in overall loss of intensity due to phase cancellation between the pore walls and the guest species, as already mentioned in the literature. ${ }^{21}$ Powder X-ray diffraction of the ruthenium containing nanomaterials $\mathbf{2 a}, \mathbf{2} \mathbf{b}$ at higher angles were investigated to check the crystalline state of the nanoparticles. The powder X-ray diffraction pattern in the $2 \theta$ range $30-60^{\circ}$ of nanomaterial $2 \mathbf{a}$ after one $\mathrm{I} / \mathrm{H}$ cycle is presented in Figure 4. It exhibits four main reflections at $38.2^{\circ}, 41.7^{\circ}, 43.6^{\circ}$ and $58.2^{\circ}$ which could be assigned to the (100), (002), (101) and (102) reflections of the hcp Ru structure. The broad width of the peaks is consistent with the small size of the nanoparticles and the fact that no large $\mathrm{Ru}$ crystals have been formed outside the pores. ${ }^{21 \mathrm{~d}}$

In order to determine more accurately the role of the phosphonate moieties in the anchorage of the ruthenium species, we carried out $\mathrm{CP}$ MAS ${ }^{31} \mathrm{P}$ and ${ }^{13} \mathrm{C}$ NMR experiments on the materials obtained after each step of the $\mathrm{I} / \mathrm{H}$ process. In addition to the expected peaks for the 
$(\mathrm{EtO})_{2} \mathrm{P}(\mathrm{O})\left(\mathrm{CH}_{2}\right)_{3}$ - moieties, the ${ }^{13} \mathrm{C}$ NMR spectrum of the material 2a after one $\mathrm{I} / \mathrm{H}$ cycle displays one peak at 67.8

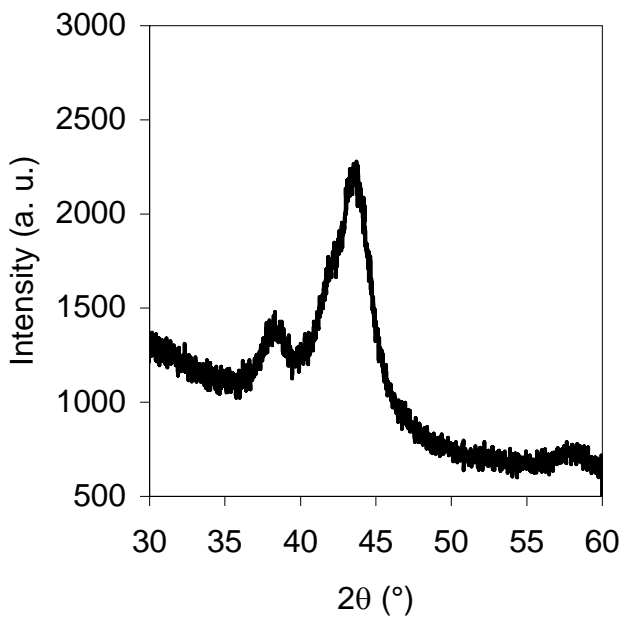

Figure 4: Powder X-ray diffraction pattern within the $2 \theta$ range $30-60^{\circ}$ for the nanomaterial $2 \mathbf{a}$ after one $\mathrm{I} / \mathrm{H}$ cycle.

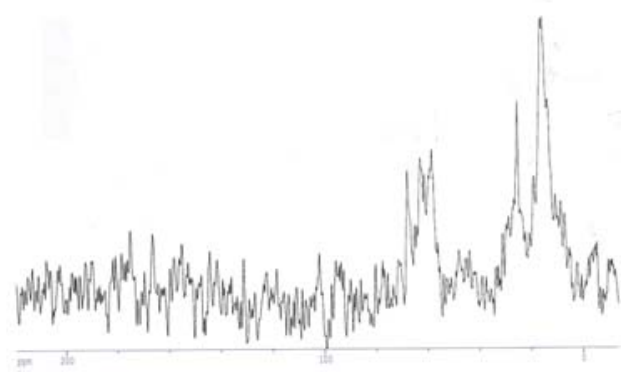

Figure 1S: Representative ${ }^{13} \mathrm{C}$ NMR spectra obtained for materials 2

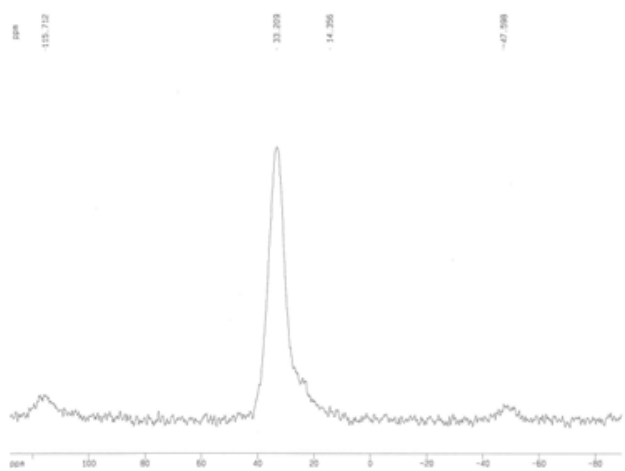

Figure 2S: Representative ${ }^{31} \mathrm{P}$ NMR spectra obtained for materials 2

ppm that could be attributed to cyclooctane but no peak corresponding to COT and COD indicating that the reduction process of the ruthenium complex ligands was complete (Figure 1S, Supplementary Information). The ${ }^{31} \mathrm{P}$ NMR spectra recorded before and after the reduction step exhibit in both cases only one peak at $33.50 \mathrm{ppm}$ characteristic of the free phosphonate group failing to evidence the coordination of the organometallic precursor or the ruthenium nanoparticles (Figure 2S, Supplementary Informa
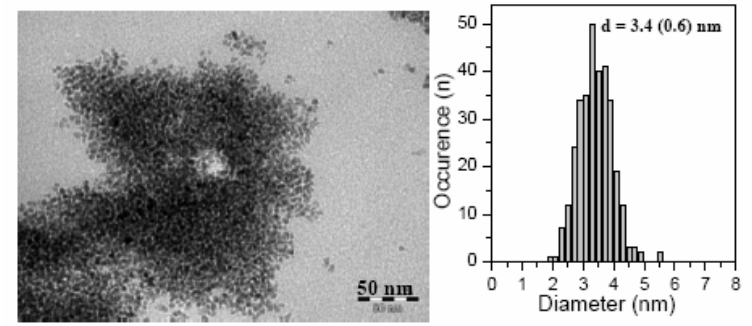

Figure 5: a) TEM image and b) size distribution (Gaussian fit) of $\mathrm{Ru}$ nanoparticles synthesized in solution with 1.8 equivalent of $(\mathrm{EtO})_{2} \mathrm{P}(\mathrm{O})\left(\mathrm{CH}_{2}\right)_{3} \mathrm{Si}(\mathrm{OMe})_{3}$.

tion). However, it is of significant importance to note that when the same impregnation procedure was applied with unfunctionalized and carboxylic acid or thiol-containing mesostructured silicas, no controlled growth of ruthenium nanoparticles within the pores of the silica matrix could be observed. This, a contrario, substantiates the role of the phosphonate moieties in the anchorage of the Ru species. To try to shed some light on the $\mathrm{Ru} /$ phosphonate affinity, we performed the synthesis of ruthenium particles in solution free of the silica matrix but in the presence of 1.8 equivalent of $(\mathrm{EtO})_{2} \mathrm{P}(\mathrm{O})\left(\mathrm{CH}_{2}\right)_{3} \mathrm{Si}(\mathrm{OMe})_{3}$ with a phosphonate/ $\mathrm{Ru}$ ratio equivalent to the one present in the functionalized silica matrix 1a. A TEM image obtained from the resulting colloidal solution is shown Figure 5. Ruthenium nanoparticles are observed which are homogeneous in size and display a mean diameter value of $3.4(0.6) \mathrm{nm}$, attesting of the stabilizing ability of the phosphonate function. Moreover, these nanoparticles are strongly aggregated as commonly observed when using a stabilizing agent exhibiting a poor affinity towards the nanoparticle surface. ${ }^{19}$ Therefore, these results suggest that strong interactions exist between the ruthenium precursor or the ruthenium nanoparticles and the phosphonate moieties.

\subsection{Thermal treatment under air to afford ruthe- nium oxide nanoparticles}

In order to get $\mathrm{RuO}_{2}$ nanoparticles-containing materials, samples 2a, $2 \mathbf{b}$ were heated under air at $2^{\circ} \mathrm{C} \cdot \mathrm{min}^{-1}$ from room temperature to $450^{\circ} \mathrm{C}$ and then annealed for 5 hours giving rise to new composite materials $\mathbf{3 a}, \mathbf{3 b}$. The thermogravimetric analysis (ATG-ATD) curves of $\mathbf{2 a}, \mathbf{2 b}$ performed under air show two weight loss steps with inflection points at 88 and $192^{\circ} \mathrm{C}$, (Figure 3S, Supplementary Information). The first weight loss can be attributed to the loss of water molecules weakly adsorbed on the silica surface, as frequently observed in the thermal behaviour of silica-based nanocomposites. ${ }^{22}$ The second weight loss with values ranging from 3 to $8 \%$ depending on the sample used corresponds to the elimination of the organic part of the silica and the formation of $\mathrm{RuO}_{2}$ nanoparticles. No further change in the weight was observed up to $500^{\circ} \mathrm{C}$. As in- 
ferred from elemental analysis (Table 1), phosphorus is not removed during the thermal process and is assumed to be

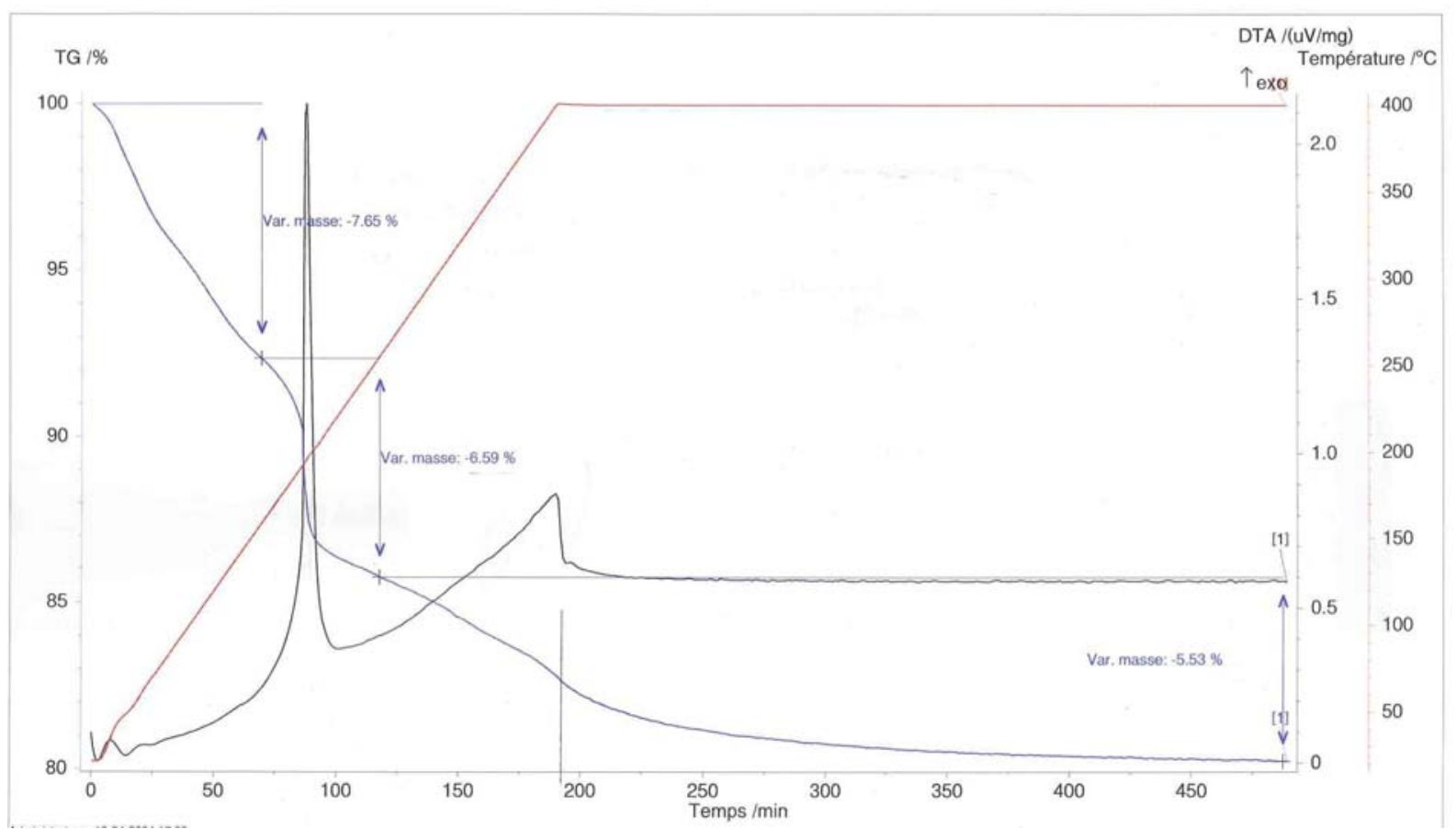

Figure 3S: Representative TGA/TDA curve obtained for the thermal treatment of materials $\mathbf{2}$ to afford materials $\mathbf{3}$

$\frac{1}{2}$

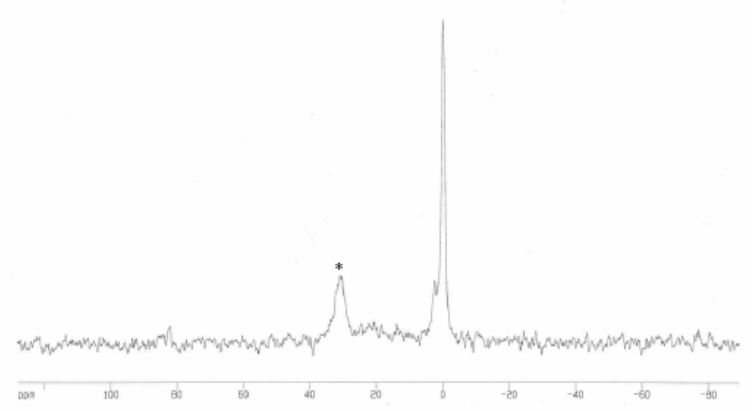

Figure 4S: Representative ${ }^{31} \mathrm{P}$ NMR spectra obtained for materials 3.* This peak can be attributed to residual phosphonate groups

present in the final materials in its phosphate form. This assumption was confirmed by recording ${ }^{31} \mathrm{P}$ NMR spectra of material 2a which display one main peak at $0.1 \mathrm{ppm}$ in agreement with the presence of a silica phosphate (Figure $4 \mathrm{~S}$, Supplementary Information). ${ }^{23}$ The effect of the thermal treatment on the structure and porosity of the host matrix was studied by nitrogen physisorption and X-ray diffraction analysis. The nanomaterials $\mathbf{3 a}$, $\mathbf{3 b}$ still present typical adsorption-desorption isotherms of type IV with an H1 hysteresis loop evidencing the preservation of the cylindrical pore volume. No significant modifications of the specific surfaces and the pore volumes were observed after the thermal treatment (Table 2). In addition, the XRD patterns in the $2 \theta$ range $0.5-5^{\circ}$ show a sharp peak due to the
(100) reflection along with the (110) and (200) reflections, clearly indicating that the mesoporous silica keeps its hex-

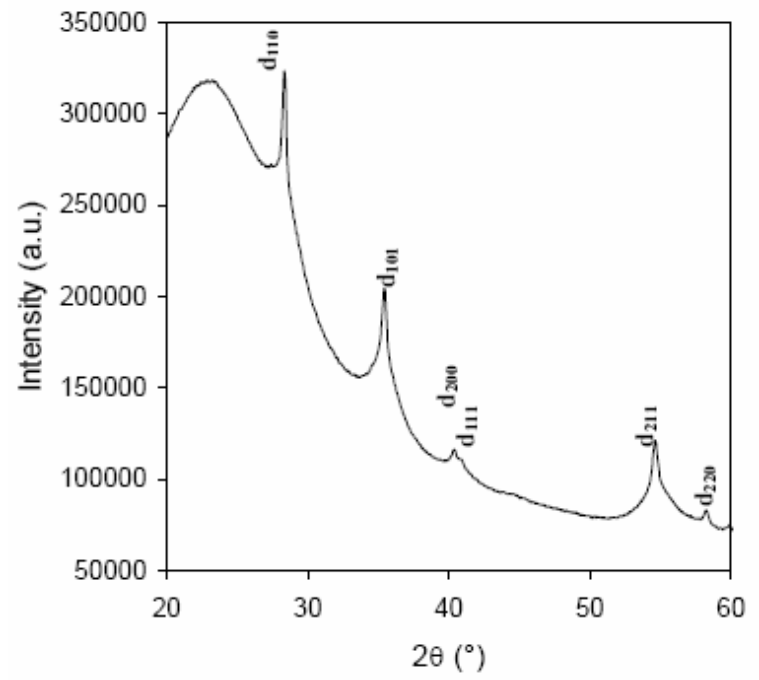

Figure 6: Powder X-ray diffraction pattern within the $2 \theta$ range $20-60^{\circ}$ for the nanomaterial $3 a$ after two $\mathrm{I} / \mathrm{H}$ cycles.

agonal structure (Table 2). The XRD pattern of nanomaterial $3 a$ in the $2 \theta$ region between 20 and $60^{\circ}$ present the main reflections at $28.1,35.2,40.4,40.9,54.5$ and $58.2^{\circ}$ which could be assigned to the (110), (101), (200), (111), (211) and (220) reflections of the tetragonal $\mathrm{RuO}_{2}$ structure (Figure 6). Finally, TEM studies carried out on $3 \mathbf{a}$ and $\mathbf{3 b}$ samples evidence the presence of the $\mathrm{RuO}_{2}$ nanoparticles inside the channels of the mesoporous silica matrices. It appears also clearly that the mesostructure of the parent hosts is not damaged during calcination process and that no external bulk metal oxide phase is present outside the 
channels. A TEM image of the nanomaterial 3a after one $\mathrm{I} / \mathrm{H}$ cycle is given in Figure 7 as example. Concerning the size of the nanoparticles, a narrow size distribution with a mean
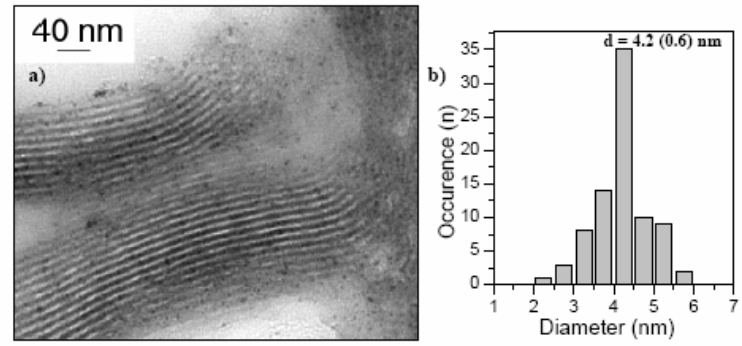

Figure 7: TEM image of nanomaterial 3a obtained after one $\mathrm{I} / \mathrm{H}$ cycle a) and $\mathrm{RuO}_{2}$ nanoparticles size distribution (Gaussian fit), b).

diameter of $4.2(0.6) \mathrm{nm}$ has been obtained for 3a (one $\mathrm{I} / \mathrm{H}$ cycle). This value is slightly larger than the one measured for the ruthenium nanoparticles in material $2 \mathbf{a}$ after one $\mathrm{I} / \mathrm{H}$ cycle $(3.4(0.5) \mathrm{nm})$ before the thermal treatment (Figure 1a). This nanoparticles size increase corresponds to a size expansion of $0.8 \mathrm{~nm}$, which is close to the theoretical size expansion expected $(1.3 \mathrm{~nm})$ for the conversion of ruthenium in ruthenium oxide. This result demonstrates that the increase in size of the nanoparticles observed after the thermal treatment is only due to the formation of the oxide network and does not result from nanoparticles coalescence.

\subsection{Evaluation of the catalytic filtering properties of the nanocomposites $3 a$}

The catalytic filtering efficiency of the composite nanomaterials 3a has been evaluated following its implementation on top of the sensitive layer of a siliconmachined gas sensor. As previously described, ${ }^{6 b, c}$ this sensor is composed of a nanostructured $\mathrm{SnO}_{2}$ sensitive layer deposited on the heating element and electric contacts of a silicon platform integrating all structures that are needed to receive and make operational the sensitive layer (Figure 8). The integration of the filtering layer was achieved through drop deposition of 3a, suspended in anisole, onto the sensitive layer followed by slow evaporation of the solvent. The working temperatures of the sensitive layer and of the filtering layer are thus under the control of a single heating resistor. A temperature gradient through the so-obtained multilayer device, lying from $450^{\circ} \mathrm{C}$ for the sensitive layer to approximately $300^{\circ} \mathrm{C}$ for the top of the filter layer, is expected when the heating resistor is supplied with 3.2 volts.

The resistance of the sensitive layer, measured through interdigited platinum electrodes, is only slightly affected when covered by the filter layer, its mean value remaining in the range $300-500 \Omega$ (at a working temperature near $450^{\circ} \mathrm{C}$, under synthetic air, and at a humidity content of $50 \%$ ). This is consistent with the expected high resistivity of the filter material, and no short-circuit of the sensitive layer is observed.

As shown in Figure 9, the presence of an "on chip" 3a filter is accompanied by strong effects on the response of the $\mathrm{SnO}_{2}$-based sensitive layer to $\mathrm{CO}, \mathrm{C}_{3} \mathrm{H}_{8}$ and $\mathrm{NO}_{2}$, i.e. important decrease of the sensitivity to $200 \mathrm{ppm}$ of $\mathrm{CO}$ and to $1.8 \mathrm{ppm}$ of $\mathrm{NO}_{2}$ ( 65 and $80 \%$ respectively) and a moderate increase $(30 \%)$ of the sensitivity to $150 \mathrm{ppm}$ of $\mathrm{C}_{3} \mathrm{H}_{8}$. Similar results have been reproduced on different series of sensors, in agreement with the homogeneous dispersion of the $\mathrm{RuO}_{2}$ nanoparticles in the host matrix observed by TEM. The efficiency of the propane discrimination is dependent on the metal content of the nanocomposite, and we observe that for $\mathrm{y} / \mathrm{x}$ values of $0.007,0.03$ and 0.07 correspond $\mathrm{S}_{\mathrm{C} 3 \mathrm{H} 8} / \mathrm{S}_{\mathrm{CO}}$ sensitivity ratios of $1.7,2.1$ and 3.2 respectively. It is also of interest to note that the non-loaded mesoporous silica has no observable effect on the $\mathrm{CO}$ and $\mathrm{C}_{3} \mathrm{H}_{8}$ sensor response instead of $\mathbf{3 a}$, evidencing the role of $\mathrm{RuO}_{2}$ nanoparticles on the observed effects.

The implementation of $\mathbf{3 a}(\mathrm{I} / \mathrm{H}=2 ; \mathrm{y} / \mathrm{x}=0.07)$ as external filter has been performed in order to evaluate the intrinsic filtering properties of this material, clear of any interactions with the sensitive layer (disturbance in the thermal exchanges, dop

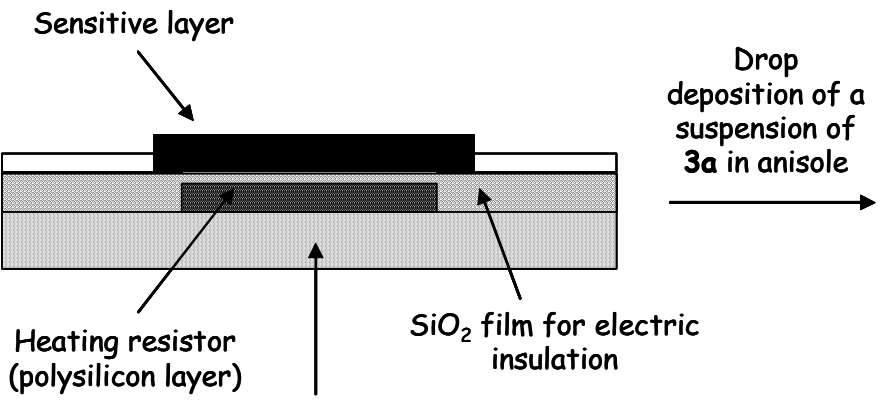

Dielectric membrane for thermal insulation

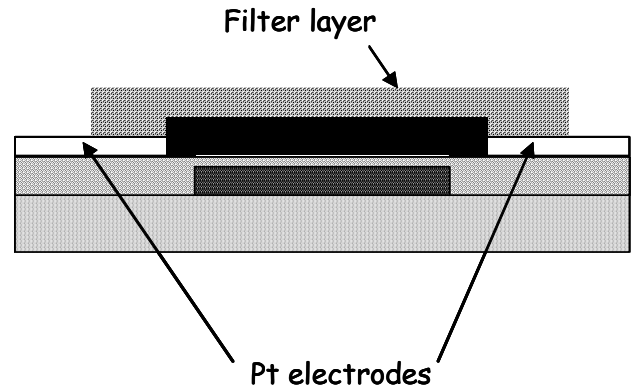


Figure 8: Schematic view of the micro sensor and of the deposition mode of the filter layer

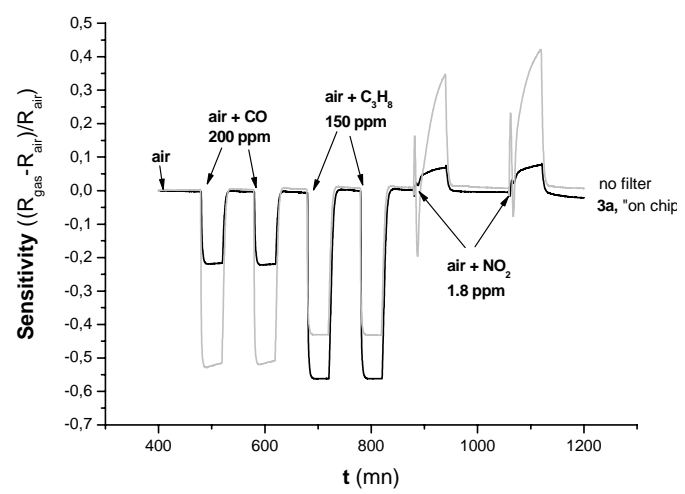

Figure 9: Sensitivity variations of the gas sensor under different gas compositions, without filter layer (grey line) and in the presence of "on chip" filter layer (black line)

ing effects through migration of $\mathrm{RuO}_{2}$ particles onto the sensitive layer...) and under accurate thermal control. Experimentally, the gas mixture is flowing through the filter material 3a, heated to $300^{\circ} \mathrm{C}$ by means of a tubular furnace, before entering into the sensor chamber. As shown in Figure 10 , a similar $65 \%$ decrease of the response to $\mathrm{CO}$ is observed, whereas the filter has no effect on the response to $\mathrm{C}_{3} \mathrm{H}_{8}$. This clearly corroborates the catalytic properties of the filter material which removes $\mathrm{CO}$ from the gas mixture by its selective oxidation into $\mathrm{CO}_{2}$, not detected by the $\mathrm{SnO}_{2}$-based sensitive layer, leaving the hydrocarbon content unaltered. The important decrease of the sensitivity to $\mathrm{NO}_{2}$ and moderate increase of the sensitivity to $\mathrm{C}_{3} \mathrm{H}_{8}$ when the filter layer is implemented on the top of the sensitive layer is assumed to be due to the migration of a small amount of $\mathrm{RuO}_{2}$ nanoparticles during the drop deposition process. The addition of a small amount of noble metal is indeed well known to modulate the response of semi conducting materials, increasing the sensitivity to reducing gases and decreasing the sensitivity to oxidizing gases.

The specific location of the catalyst into the channels of the mesoporous matrix appears to be a key point for the reproducibility and the long term stability of the observed filtering properties. When a nanocomposite material was produced following the same procedure at a similar catalyst loading but using a commercial amorphous and unfunctionalized silica (S60) with similar specific area, $\left(530 \mathrm{~m}^{2} / \mathrm{g}\right)$ and mean pore size $(5.5 \mathrm{~nm})$, we indeed observed significant differences of behavior when implemented as catalytic filter. The first difference concerns the reproducibility of the propane discrimination efficiency, which varies in a wide range from one sensor to another; the sensitivity ratios $\mathrm{S}_{\mathrm{CO}} / \mathrm{S}_{\mathrm{C} 3 \mathrm{H} 8}$ values being in the range $1.40-0.26$. In similar experimental conditions and with similar catalyst content, the mean sensitivity ratio observed for $\mathbf{3 a}$ as a catalytic filter is 0.31 with deviations limited to 0.04 around this value. The filtering efficiency of the nanocomposite based on S60 silica moreover declines quickly with time, an in- crease in the $\mathrm{S}_{\mathrm{CO}} / \mathrm{S}_{\mathrm{C} 3 \mathrm{H} 8}$ ratio of 0.44 being observed within eight days. In contrast, no variation of the filtering effi

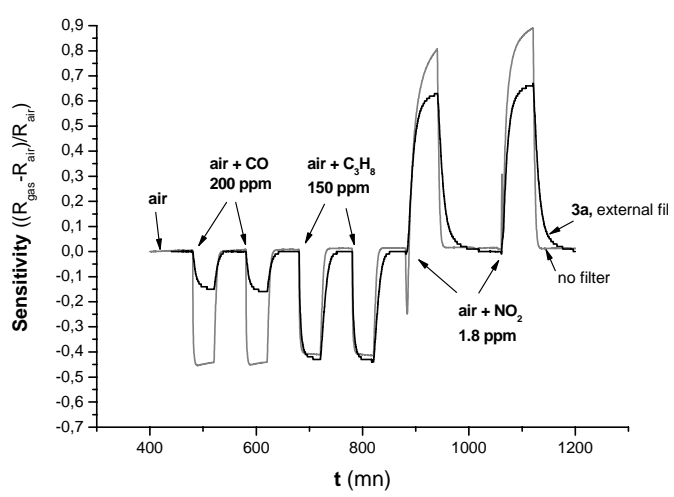

Figure 10: Sensitivity variations of the gas sensor under different gas compositions, without filter (grey line) and in the presence of an external filter (black line).

ciency of nanocomposites 3a has been observed over several weeks.

The differences we observed in the catalytic properties can be obviously related to the different morphologies of the nanocomposite materials, and particularly to the presence in 3a of phosphonate groups. This prevents their migration out of the channels of the mesoporous matrix and consequently its coalescence into larger particles.

\section{Conclusion}

In this contribution, the synthesis of novel $\mathrm{Ru} @ \mathrm{SiO}_{2}$ and $\mathrm{RuO}_{2} @ \mathrm{SiO}_{2}$ composite nanomaterials, and for the latter, their use as catalytic filters for gas sensors, are reported.

The driving force of the followed synthesis method is the combination between an organometallic approach for the preparation of metal nanoparticles and the presence of phosphonate sites within the pores of mesostructured mesoporous silicas used as hosts. These phosphonate groups allow the selective location of the metal source as $\mathrm{Ru}$ nanoparticles of $3.4 \mathrm{~nm}$ of mean size exclusively located inside the channels of the silica hosts whose mesostructure is preserved. Comparisons with previous studies clearly indicate that the mean size, of these $\mathrm{Ru}$ nanoparticles is not governed by a template effect of the host matrix. A maximum of Ru content has been reached after two $\mathrm{I} / \mathrm{H}$ cycles and no additional $\mathrm{Ru}$ incorporation could be achieved. Furthermore, the thermal treatment under air allowing the formation of $\mathrm{RuO}_{2}$ nanoparticles does not damage the host structure and does not lead to particles coalescence.

The use of $\mathrm{RuO}_{2} @ \mathrm{SiO}_{2}$ composite nanomaterials as catalytic filters for gas sensors, as well as after deposition as "on chip" filters or as external filters, revealed their very interesting catalytic behavior for the preferential detection 
of propane in a gas mixture (propane/carbon monoxide/nitrogen dioxide in air). The efficiency of the propane discrimination is dependent on the metal content of the nanocomposite materials: higher $\mathrm{Ru} / \mathrm{Si}_{\mathrm{w}}$ induced higher $\mathrm{S}_{\mathrm{C} 3 \mathrm{H} 8} / \mathrm{S}_{\mathrm{CO}}$ sensitivity ratios. The $\mathrm{RuO}_{2} @ \mathrm{SiO}_{2}$ nanomaterials partially remove $\mathrm{CO}$ from the gas mixture by its selective oxidation into $\mathrm{CO}_{2}$, leaving the hydrocarbon content unaltered. The catalytic behavior of these $\mathrm{RuO}_{2} @ \mathrm{SiO}_{2}$ nanomaterials is greatly enhanced in comparison with the one of another hybrid nanomaterial similarly prepared with an unfunctionalized commercial silica for which not well dispersed nanoparticles in the silica grains were observed. The presence of phosphonate groups inside the channels of the hosts is then crucial: 1) it allows a directed growth of controlled sized particles exclusively inside the pores with a homogeneous dispersion throughout the host structure, 2) it limits significantly nanoparticles sintering and 3 ) it leads to reproducible results.

In summary, this synthesis method appears as a simple and reproducible way to produce well-controlled composite metal or metal oxide containing silica nanomaterials displaying interesting catalytic properties that has been evidenced in a gas sensing application. This study demonstrates that a single approach, deposition of a catalyst suspended in a liquid, may allow the modulation of sensitivity of gas sensors; it also shows that the nature of the material employed is critical in order to obtain reproducible results. However, although we observed an important and reproducible increase in selectivity for propane in the presence of $\mathrm{CO}$ and $\mathrm{NO}_{2}$, we did not succeed to completely eliminate $\mathrm{CO}$ response by selective oxidation into $\mathrm{CO}_{2}$. This may result from $\mathrm{CO}$ diffusion at the grain boundaries. Further work will be necessary to optimize a material able to reach this goal.

\section{Experimental Section}

\subsection{Synthesis and implementation of the catalytic filter}

Hybrid organic-inorganic mesostructured materials $(\mathrm{EtO})_{2} \mathrm{P}\left(\mathrm{CH}_{2}\right)_{3} \mathrm{SiO}_{1.5} / \mathrm{xSiO}_{2}(\mathrm{x}=9: \mathbf{1 a}, \mathrm{x}=16: \mathbf{1 b}),{ }^{24}$ were synthesized as reported elsewhere. Unfunctionalized mesostructured silica was prepared by the method of Stucky and co-workers. ${ }^{25}[\mathrm{Ru}(\mathrm{COD})(\mathrm{COT})]$ was prepared following an adapted published procedure. $^{26}$ $(\mathrm{EtO})_{2} \mathrm{P}(\mathrm{O})\left(\mathrm{CH}_{2}\right)_{3} \mathrm{Si}(\mathrm{OMe})_{3}$ was prepared by addition of $14.5 \mathrm{~g}(50 \mathrm{mmol})$ of 3-iodopropyltrimethoxysilane to $\mathrm{P}(\mathrm{OEt})_{3}(20 \mathrm{~g}, 120 \mathrm{mmol})$. The mixture was heated under reflux $24 \mathrm{~h}$ under Ar, then, the excess of $\mathrm{P}(\mathrm{OEt})_{3}$ was removed in vacuo. $\mathrm{Bp}_{5}{ }^{-2}{ }_{\mathrm{mbar}}: 120^{\circ} \mathrm{C}$. Yield : $10.5 \mathrm{~g} \mathrm{(70 \% ).}$ ${ }^{13} \mathrm{C} \mathrm{NMR}\left(\mathrm{CDCl}_{3}, 50 \mathrm{MHz}\right) \delta 9.6,16.3,27,29.4,50.3,61.4$ ppm; ${ }^{29} \mathrm{Si}-\mathrm{NMR}\left(\mathrm{CDCl}_{3}, 40 \mathrm{MHz}\right) \delta-43 \mathrm{ppm} ;{ }^{31} \mathrm{P} \mathrm{NMR}$ $\left(\mathrm{CDCl}_{3}, 81 \mathrm{MHz}\right) \delta 32.68 \mathrm{ppm}$. Elemental analysis: $\mathrm{Si} / \mathrm{P}$ 1.02. Tetrahydrofuran (THF) was purified under standard procedure and distilled under nitrogen atmosphere prior to use. All experiments were carried out using conventional schlenk tube and vacuum/argon-line techniques. Hydrogenation reactions were performed using Fisher-Porter bottles.

\section{Synthesis of the Ru@SiO ${ }_{2}$ composites.}

A simple two-step procedure i.e. impregnation/hydrogenation $(\mathrm{I} / \mathrm{H})$ was followed to prepare the ruthenium nanoparticles containing nanocomposites. One, two or three $\mathrm{I} / \mathrm{H}$ cycles were applied to the mesostructured materials $(\mathrm{EtO})_{2} \mathrm{P}(\mathrm{O})\left(\mathrm{CH}_{2}\right)_{3} \mathrm{SiO}_{1.5} / \mathrm{xSiO}_{2}(\mathrm{x}=9$ : 1a, $\mathrm{x}=16$ : 1b) or commercial S60 silica (Merck). In a typical experiment, $150 \mathrm{mg}$ of the hybrid organic-inorganic mesoporous material $(\mathrm{EtO})_{2} \mathrm{P}(\mathrm{O})\left(\mathrm{CH}_{2}\right)_{3} \mathrm{SiO}_{1.5} / 16 \mathrm{SiO}_{2}$ 1b were suspended in $2 \mathrm{~mL}$ of THF. [Ru(COD)(COT)] (35.0 mg, 0.11 $\mathrm{mmol}$ ) in $2 \mathrm{~mL}$ of THF was added and the resulting mixture stirred for 24 hours. The solvent was filtered off and the resulting powder dried in vacuo for 24 hours. The resulting powder was placed in a Fisher-Porter bottle under 3 bars of dihydrogen at room temperature for 48 hours giving rise to $\mathrm{Ru} @ \mathrm{SiO}_{2}$ solids.

\section{Synthesis of the RuO $\mathrm{O}_{2} @ \mathrm{SiO}_{2}$ composites.}

The powder resulting from the $\mathrm{I} / \mathrm{H}$ steps was heated under air at $2^{\circ} \mathrm{C} . \mathrm{min}^{-1}$ from room temperature to $450^{\circ} \mathrm{C}$ and then annealed for 5 hours, producing $\mathrm{RuO}_{2} @ \mathrm{SiO}_{2}$ as dark green solids.

Implementation of the nanocomposite materials as "on chip" catalytic filter.

Anisole suspensions of the nanocomposite material were dropped onto the $\mathrm{SnO}_{2}$-based sensitive layer of a micro chemical sensor device integrating all structures that are needed to make operational a sensing layer (heater, metal electrodes, membrane, insulating layer, etc...). The integrated polysilicon heater $(600 \times 430 \mu \mathrm{m})$ of the sensor, supplied through platinum electrodes, was used to in situ evaporate the solvent and stabilize the sensitive and filter layers set according to an optimized multi-step temperature profile. The heater can reach a maximal temperature of $500^{\circ} \mathrm{C}$ with a power consumption of $100 \mathrm{~mW}$. The sensitive layer resistance was measured between interdigited platinum electrodes.

Implementation of the nanocomposite materials as external catalytic filter.

The nanocomposite material $(200 \mathrm{mg})$ was inserted and immobilized in a tubular chamber so that the test gas can only pass the chamber through the filter material before reaching the sensor chamber. The chamber for filter material is placed into a tubular furnace heated at $300^{\circ} \mathrm{C}$.

Measurements under gases. 
A computer-controlled gas test bench was used to characterize the filter materials. It consists of a gas delivery system, glass sensor chambers and a measurement bridge for resistance determinations. Operating mode and data acquisition and processing were controlled through Labwindows software (National Instruments). Tests have been systematically performed by mean of a set of eight sensors similarly processed and exposed to a stream of synthetic air containing successively $200 \mathrm{ppm}$ of carbon monoxide, 150 ppm of propane, and $1.8 \mathrm{ppm}$ of nitrogen dioxide, under a relative humidity of $50 \%$ and at a flow rate of 1000 $\mathrm{mL} / \mathrm{min}$. The working temperature of the sensitive layer of each sensor was near $450^{\circ} \mathrm{C}$.

\subsection{Physical Measurements}

Thermogravimetric analyses (TGA, DTA) were performed on a NETZSCH STA 409 PC LUXX instrument. Elemental analyses were performed at the Service Central d'Analyse (CNRS, Vernaison, France). Powder X-ray diffraction patterns were measured on a PanAnalytical diffractometer equipped with an ultra-fast X'celerator detector X'pert Pro with Nickel-filtered copper radiation (1.5405 $\AA)$. The measurement parameters are: step size, 0.01671; counting time, $60 \mathrm{~s}$ (Institut Européen des Membranes UMR 5635 ENSCH-UMII-CNRS, Montpellier, France). Solid samples for Transmission Electron Microscopy (TEM) measurements were prepared using ultramichrotomy techniques and then deposited on copper grids. TEM measurements were carried out at $100 \mathrm{kV}$ with a microscope JEOL 1200 EXII (Service Commun de Microscopie Electronique, Université Montpellier II, Montpellier, France). Solution samples for TEM were prepared by slow evaporation of a drop of crude colloidal solution deposited

\section{References and Notes}

[1] (a) T. Hyeon, Chem. Commun., 2003, 927; (b) K. J. Klabunde, in Nanoscale Materials in Chemistry, ed. K. J. Klabunde, Wiley Intersciences, New York, 2001; (c) M. R. Diehl, J.-Y. Yu, J. R. Heath, G. A. Doyle, S. Sun, C. B. Murray, J. Phys. Chem. B, 2001, 105, 7913; (d) D. L. Leslie-Pelescky, R. D. Rieke, Chem. Mater., 1996, 8, 1770.

[2] (a) D.E. Williams, in Solid State gas sensors, ed. P.T. Moseley and B.C. Tofield, Adam Hilger, Bristol, 1987, p. 71. (b) V. Lantto, in Gas Sensors, Principle, Operation and Developments, ed. G. Sberveglieri, Kluwer Academic, Dordrecht, Boston, London, 1992, p. 117. (c) K. Ihokura and J. Watson, The Stannic Oxide Gas Sensor: Principles and Applications, CRC Press, Boca Raton, FL, 1994.

[3] Figaro Engineering Inc. website.

[4] (a) N. Yamazoe, Sens. Actuators, B, 1991, 5, 7-19. (b) W. Göpel in Gas Sensors: Principle, Operation and Developments, Ed. G. Sberveglieri, Kluwer Academic Dordrecht, Boston, London, 1992, p. 365. (c) G. Sberveglieri, Sens. Actuators, B, 1995, 23, 103.

[5] (a) C. Nayral, E. Viala, P. Fau, F. Senocq, J. - C. Jumas, A. Maisonnat, B. Chaudret, Chem. Eur. J., 2000, 6, 4082. (b) P. Fau, M. Sauvan, S. Trautweiler, C. Nayral, L. Erades, A. onto carbon covered copper grids under argon. TEM analyses were performed at the "Service Commun de Microscopie Electronique de l'Université Paul Sabatier" (TEMSCAN) on a JEOL 200CX-T electron microscope operating at $200 \mathrm{kV}$ with a resolution point of $4.5 \AA$. The nanoparticle size distribution histograms were determined using enlarged TEM micrographs. The size distribution of the particles was determined by measuring a minimum of 200 particles for each sample. The size distributions observed are generally likely to be analysed in terms of Gaussian statistic. The CP MAS ${ }^{31} \mathrm{P}$ and ${ }^{13} \mathrm{C}$ solid state NMR spectra were recorded on a BRUKER FTAM 300 solid state NMR spectrometer.

\section{Acknowledgements}

The authors thank Dr. Arie van der Lee (IEM, UMR5635, Montpellier, France) for XRD measurements, CNRS (PICS N²428), Région Midi-Pyrénées (CTP $\left.\mathrm{N}^{\circ} 03007519\right)$ and Languedoc-Roussillon (CTP $\left.\mathrm{N}^{\circ} 249 \mathrm{R}\right)$ for financial support. S. J. thanks CNRS-DFGT and J. G-A thanks del Ministerio de Educatión y Ciencia de Espaňa for a postdoctoral fellowship (EX2004-0039).

Maisonnat, B. Chaudret, Sens. Actuators, B, 2001, 78, 83. (c) K. Soulantica, L. Erades, M. Sauvan, F. Senocq, A. Maisonnat, B. Chaudret, Adv. Funct. Mater., 2003, 13, 553. (d) L. Erades, D. Grandjean, C. Nayral, K. Soulantica, B. Chaudret, P. Menini, F. Parret, A. Maisonnat, New J. Chem., 2006, 30, 1026.

[6] (a) V. Demarne, A. Grisel, Sens. Actuators, B, 1993, 15/16, 63. (b) P. Fau, M. Sauvan, S. Trautweiler, C. Nayral, L. Erades, A. Maisonnat, B. Chaudret, Sens. Actuators, B, 2001, 78, 83. (c) B. Chaudret, L. Erades, P. fau, A. Maisonnat, C. Nayral, J. -L. Simon, PCT Int. Appl. WO 002844, 2001.

[7] A. Heilig, N. Barsan, U. Weimar, M. Schweizer-Berberich, J.W. Gardner, W. Göpel, Sens. Actuators, B, 1997, 43, 45.

[8] (a) I. Simon, N. Barsan, M. Bauer, U. Weimar, Sens. Actuators, B, 2001, 73, 1. (b) M. Schweizer-Berberich, M. Zdralek, U. Weimar, W. Göpel, T. Viard, D. Martinez, A. Seube, A. Peyre-Lavigne, Sens. Actuators, B, 2000, 65, 91. (c) F. Parret, P. Menini, A. Martinez, K. Soulantica, A. Maisonnat, B. Chaudret, Sens. Actuators, B, 2006, 118, 276. (d) M. Baumbach, A. Sossong, H. Delprat, K. Soulantica, 
A. Schütze, H. Borrel, A. Maisonnat, B. Chaudret, Proceedings of IEEE Sensors Conference, 2005, 91.

[9] (a) A. Katsuki, K. Fukui, Sens. Actuators, B, 1998, 52, 30. (b) C. H. Kwon, D. H. Yun, H.-K. Hong, S.-R. Kim, K. Lee, H. Y. Lim, K. H. Yoon, Sens. Actuators, B, 2000, 65, 327. (c) R. K. Sharma, P. C. Chan, Z. Tang, G. Yan, I.-M. Hsing, J. K.-O. Sin, Sens. Actuators, B, 2001, 72, 160. (d) P. Montmeat, C. Pijolat, G. Tournier, J. P. Viricelle, Sens. Actuators, B, 2002, 84, 148. (e) A. Cabot, J. Arbiol, A. Cornet, J. R. Morante, F. Chen, M. Liu, Thin Solid Films, 2003, 436, 64. (f) J. Arbiol, A. Cabot, J. R. Morante, F. Chen, M. Liu, Appl. Phys. Lett., 2002, 81, 3449.

[10] (a) L. M. Bronstein, Top. Curr. Chem., 2003, 266, 55. (b) J.L. Shi, Z.-L. Hua, L.-X. Zhang, J. Mater. Chem., 2004, 14, 795.

[11] (a) J. S. Beck, C. T.-W. Chu, I. D. Johnson, C. T. Kresge, M. E. Leonowicz, W. J. Roht, J. W. Vartuli, WO Patent 91/11390, 1991. (b) C. T. Kresge, M. E. Leonowicz, W. J. Roth, J. C. Vartuli, J. S. Beck, Nature, 1992, 359, 710. (c) J. S. Beck, J. C. Vartuli, W. J. Roht, M. E. Leonowicz, C. T. Kresge, K. D. Schmitt, C. T. W. Chu, D. H. Olson, E. W. Sheppard, S. B. McCullen, J. B. Higgins, J. L. Schlender, J. Am. Chem. Soc., 1992, 114, 10834.

[12] Taguchi, F. Schüth, Micropor. Mesopor. Mater., 2005, 77, 1.

[13] a) C. R. Patra, A. Ghosh, P. Mukherhee, M. Sastry, R. Kumar, Stud. Surf. Sci. Catal., 2002, 141, 641. (b) P. Mukherjee, C. R. Patra, R. Kumar, M. Sastry, Phys. Chem. Commun., 2001, 5, 1. (c) K.-J. Chao, M.-H. Cheng, Y.-F. Ho, P.-H. Liu, Catal. Today, 2004, 97, 49. (d) Y. Guari, C. Thieuleux, A. Mehdi, C. Reye, R. J. P. Corriu, S. GomezGallardo, K. Philippot, B. Chaudret, R. Dutartre, Chem. Commun., 2001, 1374. (e) Y. Guari, C. Thieuleux, A. Mehdi, C. Reye, R. J. P. Corriu, S. Gomez-Gallardo, K. Philippot, B. Chaudret, Chem. Mater., 2003, 15, 2017.

[14] X.-G. Zhao, J.-L. Shi, B. Hu, L.-X. Zhang, Z.-L. Hua, Mater. Lett., 2004, 58, 2152.

[15] Y. S. Cho, J. C. Park, B. Lee, Y. Kim, J. Yi, Catal. Lett., 2002, 81, 89.

[16] Y. Guari, K. Soulantica, K. Philippot, C. Thieuleux, A. Mehdi, C. Reye, B. Chaudret, R. J. P. Corriu, New J. Chem., 2003, 27, 1029.

[17] a) C.-M. Yang, P.-H. Liu, Y.-F. Ho, C.-Y. Chiu, K.-J. Chao, Chem. Mater., 2003, 15, 275. (b) L.-X. Zhang, J.-L. Shi, J.
Yu, Z.-L. Hua, X.-G. Zhao, M.-L. Ruan, Adv. Mater., 2002, 14,1510 .

[18] B. Chaudret in Top Organomet Chem., eds C. Copéret and B. Chaudret, Springer-Verlag Berlin Heidelberg, 2005, 16, 233.

[19] (a) C. Pan, K. Pelzer, K. Philippot, B. Chaudret, F. Dassenoy, P. Lecante, M.-J. Casanove, J. Am. Chem. Soc., 2001, 123, 7584. (b) S. Jansat, M. Gómez, K. Philippot, G. Muller, E. Guiu, C. Claver, S. Castillón and B. Chaudret, J. Am. Chem. Soc., 2004, 126, 1592. (c) E. Ramirez, S. Jansat, K. Philippot, P. Lecante, M. Gomez, A. M. Masdeu-bulto, B. Chaudret, J. Organomet. Chem., 2004, 689, 4601. (d) M. Tristany, B. Chaudret, P. Dieudonné, Y. Guari, P. Lecante, V. Matsura, M. Moreno-Manas, K. Philippot, R. Pleixats, Adv. Funct. Mater., 2006, 16, 2008.

[20] a) V. Hulea, D. Brunel, A. Galarneau, K. Philippot, B. Chaudret, P. J. Kooyman, F. Fajula, Micropor. Mesopor. Mater., 2005, 79, 185. (b) H.-P. Kormann, G. Schmid, K. Pelzer, K. Philippot, B. Chaudret, Z. Anorg. Allg. Chem., 2004, 630, 1913. (c) A. Spitaleri, P. Pertici, C. Evangelisti, A. M. Caporusso, G. Vitulli, G. Capannelli, M. Hoang, T. W. Turney, J. Organomet. Chem., 2004, 689, 639.

[21] (a) F. J. Brieler, M. Fröba, L. Chen, P.J. Klar, W. Heimbrodt, Chem. Eur. J., 2002, 8, 185. (b) W. Hammond, E. Prouzet, S. D. Mahanti, T. Pinnavaia, Microporous Mesoporous Mater., 1999, 27, 19. (c) M. Froba, R. Köhn, G. Bouffaud, Chem. Mater., 1999, 11, 2858. (d) F. J. Brieler, P. Gurndmann, M. Fröba, L. Chen, P. J. Klar, W. Heimbrodt, H.-A. K. von Nidda, T. Kurz, A. Loidl, J. Am. Chem. Soc., 2004, 126, 797.

[22] (a) B. Folch, J. Larionova, Y. Guari, Ch. Guérin, A. Mehdi, C. Reyé, J. Mater. Chem., 2004, 14, 2703. (b) B. Folch, J. Larionova, Y. Guari, L. Datas, Ch. Guérin, J. Mater. Chem., 2006, 16, 4435.

[23] I. Lukes, M. Borbaruah, L. D. Quin, J. Am. Chem. Soc., 1994, 116, 1737.

[24] R. J. P. Corriu, L. Datas, Y. Guari, A. Mehdi, C. Reye, C. Thieuleux, Chem. Commun., 2001, 763.

[25] D. Zhao, J. Geng, Q. Huo, N. Melosh, G. H. Fredrickson, B. F. Chmelka, G. D. Stucky, Science, 1998, 279, 548. (b) D. Zhao, Q. Huo, J. Feng, B. F. Chmelka, G. D. Stucky, J. Am. Chem. Soc., 1998, 120, 6024.

[26] P. Pertici, G. Vitulli, Inorg. Synth., 1983, 22, 176 